\title{
Estádio de Desenvolvimento e Superfície Foliar Reduzem a EficiênCia de Chlorimuron-EThyl e Glyphosate em Conyza sumatrensis ${ }^{1}$
}

\author{
Developmental Stage and Leaf Surface Reduce the Efficiency of Chlorimuron-Ethyl and \\ Glyphosate in Conyza sumatrensis
}

\author{
SANTOS, F.M. ${ }^{2}$, VARGAS, L. ${ }^{3}$, CHRISTOFFOLETI, P.J. ${ }^{4}$, AGOSTINETTO, D. ${ }^{5}$, MARTIN, T.N. ${ }^{6}$, \\ RUCHEL, Q. ${ }^{5}$ e FERNANDO, J.A. ${ }^{5}$
}

\begin{abstract}
RESUMO - Nos Estados do Rio Grande do Sul e do Paraná, há frequentes relatos de falhas de controle de Conyza sumatrensis com chlorimuron-ethyl em lavouras de soja. Assim, os objetivos deste trabalho foram caracterizar morfologicamente as folhas de Conyza sumatrensis e avaliar o controle com herbicidas aplicados em biótipos dessa planta daninha em três estádios de desenvolvimento. Foram realizados dois estudos, com experimentos em casa de vegetação, em delineamento inteiramente casualizado com quatro repetições. No primeiro estudo, os biótipos de buva foram coletados e identificados; já no segundo estudo avaliou-se a resposta de biótipos aos herbicidas, doses e estádios de desenvolvimento. As doses de herbicidas foram: 0,0; 6,25; 12,$5 ; 25 ; 50 ; 100 ; 200$; e 400, representadas em porcentagem da dose de registro dos herbicidas chlorimuron-ethyl $\left(20 \mathrm{~g} \mathrm{ha}^{-1}\right)$ e glyphosate $\left(720 \mathrm{~g}\right.$ e.a. $\left.\mathrm{ha}^{-1}\right)$, aplicadas de modo isolado ou associadas em três estádios de desenvolvimento dos quatro biótipos $(2,5,17$ e 20) de Conyza sumatrensis (altura de 0,5-1 cm e 3-4 folhas; altura 1-2 cm e 6-7 folhas; e altura de 10-12 cm e 12-14 folhas). As variáveis analisadas foram controle, fitomassa seca da parte aérea e as densidades tricomática e estomática da superficie foliar dos biótipos em diferentes estádios de desenvolvimento. Os resultados demonstram que os estádios de desenvolvimento alteram a eficácia dos herbicidas, e aplicações em estádios avançados de desenvolvimento diminuem a eficácia de controle. A exceção foi o biótipo 5 de Conyza sumatrensis, que demonstrou resistência ao glyphosate, independentemente do estádio de desenvolvimento no momento da aplicação do herbicida. Houve variação no número de tricomas entre os biótipos em todos os estádios de desenvolvimento, e o número de estômatos diminuiu com o desenvolvimento dos biótipos.
\end{abstract}

Palavras-chave: buva, planta daninha, ALS, EPSPs, tricomas, estômatos.

\begin{abstract}
In the states of Rio Grande do Sul and Paraná, there are frequent reports of failure to control Conyza sumatrensis with chlorimuron-ethyl in soybean crops. Thus, the objectives of this study were to characterize Conyza sumatrensis leaves morphologically and evaluate herbicide control in biotypes of this weed at three stages. Two studies were conducted, with experiments in a greenhouse in a completely randomized design with four replications. In the first study, horseweed biotypes were collected and identified, and the second study evaluated the responses of herbicide rates and development stages. The herbicide rates were: 0.0, 6.25, 12.5, 25, 50, 100, 200 and 400, represented as a percentage of the dose registry of herbicides chlorimuronethyl $\left(20 \mathrm{~g} \mathrm{ha}^{-1}\right)$ and glyphosate $\left(720 \mathrm{ge.a.} \mathrm{ha}^{-1}\right)$ applied in isolation or associated at three developmental stages of four Conyza sumatrensis (2, 5,17 and 20) biotypes (height $=0.5-1 \mathrm{~cm}$ and 3-4 leaves, height $=1-2 \mathrm{~cm}$ and 6-7 leaves, height $=10-12 \mathrm{~cm}, 12-14$ leaves). The variables analyzed were control, shoot dry weight and trichome and stomatal densities biotypes of the leaf surface at different stages of development. The results obtained demonstrate that the developmental stages affect the effectiveness of the herbicides, and applications at advanced stages of development decrease the effectiveness of control. The exception was biotype 5 of Conyza sumatrensis, which shows resistance to glyphosate, regardless of stage of development at the time of herbicide application. There was variation in the number of trichomes among biotypes at all stages of development, and the number of stomata decreased with the development of biotypes.
\end{abstract}

Keywords: horseweed, weed, ALS, EPSPs, trichomes, stomata.

Recebido para publicação em 6.12.2013 e aprovado em 28.1.2014.

IFRS, campus Sertão, Sertão-RS, Brasil, <fernando.machado@sertao.ifrs.edu.br>; ${ }^{3}$ Embrapa Trigo, Passo Fundo-RS, Brasil;

${ }^{4}$ ESALQ/USP, Piracicaba-SP, Brasil, ${ }^{5}$ UFPel, Capão do Leão-RS, Brasil; ${ }^{6}$ UFSM, Santa Maria-RS, Brasil. 


\section{INTRODUÇÃO}

Conyza sumatrensis, popularmente conhecida como buva, pertence à classe botânica das magnoliopsidas e à família Asteraceae. É uma planta herbácea identificada como planta daninha em lavouras de soja no Brasil, considerada, junto com Conyza canadensis, a espécie mais difundida em todo o mundo (Thebaud \& Abbott, 1995). Esse gênero apresenta plantas com elevado potencial competitivo e dispersivo, podendo causar danos diretos e indiretos às culturas. A cultura da soja, cultivada em sistema de semeadura direta, apresentou perda de produtividade de $83 \%$ quando em presença de 150 plantas de C. canadensis por $\mathrm{m}^{2}$ (Bruce $\&$ Kells, 1990).

A buva (Conyza spp.) é uma das principais plantas daninhas em lavouras de soja na região Sul do Brasil. Essa espécie foi selecionada nas lavouras de soja transgênica resistente a glyphosate devido ao uso repetido de glyphosate, que resultou em aumento da pressão de seleção. Já foi comprovada a resistência ao glyphosate em biótipos de C. bonariensis e C. canadensis, no Rio Grande do Sul (Vargas et al., 2007; Lamego \& Vidal, 2008), e de C. sumatrensis, no Paraná (Santos, 2012).

O mecanismo de ação do glyphosate é bastante singular, por ser o único herbicida capaz de inibir especificamente a 5-enolpiruvilchiquimato-3-fosfato sintase (EPSPs), que é a responsável pela reação de conversão do chiquimato-3-fosfato e fosfoenolpiruvato em EPSP e fosfato inorgânico na rota do ácido chiquímico (Geiger $\&$ Fuchs, 2002). Com o surgimento de resistência a esse mecanismo de ação, outros herbicidas passaram a ser associados ao glyphosate para melhorar o controle de Conyza spp., entre eles o chlorimuron-ethyl. Esse herbicida atua na inibição da acetolactato sintase (ALS) e interrompe a sintese de proteína, que por sua vez interfere na síntese de DNA e no crescimento celular (Rodrigues \& Almeida, 2011).

Até o momento foi identificado um caso de $C$. bonariensis resistente aos inibidores de ALS em Israel. Já para C. canadensis foram identificados sete casos, sendo um caso com resistência múltipla em Israel; quatro nos
Estados Unidos, em diferentes estados, com dois casos de resistência múltipla em dois; um na Polônia; e um no Canadá, com resistência múltipla (Heap, 2013). A resistência múltipla ocorre quando um biótipo possui dois ou mais mecanismos de resistência distintos que conferem o comportamento resistente a um ou vários herbicidas com diferentes mecanismos de ação (Christoffoleti et al., 2008). Para C. sumatrensis, foram identificados dois casos de resistência a ALS no Brasil, sendo um deles com resistência múltipla (Heap, 2013).

Além da resistência dos biótipos de buva aos inibidores da EPSPs e ALS, outro fator que interfere muito no manejo dessa espécie é o estádio de desenvolvimento das plantas no momento da aplicação do herbicida (Koger et al., 2004). O estádio de desenvolvimento, a morfologia, a absorção, a translocação, as condições ambientais, a época de aplicação e o metabolismo são importantes fatores que determinam a seletividade do herbicida nas plantas. Vangessel et al. (2009) avaliaram a interação entre doses de glyphosate e o estádio de desenvolvimento da buva (biótipo resistente) e observaram que em plantas jovens (estádios iniciais) os niveis de controle são melhores. Segundo Moreira et al. (2010), quanto mais avançado o estádio das plantas de buva, maior a ocorrência de brotações laterais após a aplicação dos herbicidas.

Outro fator que pode influenciar a sensibilidade dos herbicidas nos biótipos de Conyza spp. está relacionado às características anatômicas da folha. De acordo com Procópio et al. (2003), as principais barreiras foliares potenciais à penetração de herbicidas em C. bonariensis são: alta densidade tricomática; grande espessura da cutícula da face adaxial; baixa densidade estomática na face adaxial; e a presença de cera epicuticular, principalmente na face adaxial. Assim, é provável que essas características presentes nas folhas de Conyza spp. interceptem e/ou diminuam a absorção das gotas do herbicida pulverizado, impedindo que elas alcancem a epiderme propriamente dita, conferindo maior ou menor grau de sensibilidade aos biótipos tratados.

Objetivou-se com este trabalho caracterizar morfologicamente as folhas de Conyza sumatrensis e avaliar o controle com 
herbicidas aplicados em biótipos dessa planta daninha em três estádios de desenvolvimento.

\section{MATERIAL E MÉTODOS}

Foram conduzidos dois estudos em casa de vegetação, em Passo Fundo/RS (S 28¹5’46" e W 52'24'24", a $684 \mathrm{~m}$ de altitude). O delineamento experimental adotado foi o inteiramente casualizado com quatro repetições. No primeiro estudo foram coletados quatro biótipos de buva, identificados na Tabela 1. Foram confeccionadas exsicatas desses biótipos e enviadas ao Departamento de Biologia da Universidade Federal de Santa Maria, onde foram catalogadas e classificadas como Conyza sumatrensis (Teles et al., 2013), sendo depositadas no herbário sob os números SMDM 13950, SMDM 13951, SMDM 13952 e SMDM 13953.

No segundo estudo, a semeadura ocorreu em 27/4/2012, em vasos plásticos (unidades experimentais) com capacidade para $500 \mathrm{~mL}$, contendo substrato da Garden Plus Turfa Fértil ${ }^{\circledR}$. Após a emergência, ocorrida em 06/05/2012, foi realizado desbaste, deixando-se três plantas por vaso. Nesse estudo foi avaliada a resposta de cada biótipo de $C$. sumatrensis $(2,5,17$ e 20) (Tabela 1 ) aos herbicidas chlorimuron-ethyl $(0,0 ; 1,25 ; 2,5$; $5 ; 10 ; 20 ; 40$; e $\left.80 \mathrm{~g} \mathrm{ha}^{-1}\right)$, glyphosate $(0 ; 45$; 90; 180; 360; 720; 1.440; e 2.880 g e.a. ha-1) e à associação de chlorimuron-ethyl + glyphosate $(0,0 ; 1,25+45 ; 2,5+90 ; 5+180$; $10+360 ; 20+720 ; 40+1.440 ; 80 \mathrm{~g}+$ 2.880 g e.a. ha ${ }^{-1}$ ), representando 0,$0 ; 6,25$; 12,$5 ; 25 ; 50 ; 100 ; 200$; e $400 \%$ da dose de registro de chlorimuron-ethyl $\left(20 \mathrm{~g} \mathrm{ha}^{-1}\right)$ e de glyphosate (720 g e.a. ha-1) (Rodrigues \& Almeida, 2011).

No tratamento com chlorimuron-ethyl isolado, adicionou-se $0,05 \% \mathrm{v} \mathrm{v}^{-1}$ de Assist ${ }^{\circledR}$ (adjuvante hidrocarboneto alifático $756 \mathrm{~g} \mathrm{~L}^{-1}$ ). Os tratamentos herbicidas foram aplicados em três estádios de desenvolvimento (altura de 0,5-1 cm e 3-4 folhas; altura de $1-2 \mathrm{~cm}$ e 6-7 folhas; e altura de 10-12 cm e 12-14 folhas) em cada biótipo.

As aplicações dos tratamentos ocorreram nos dias 13/6/2012, 2/7/2012 e 23/7/2012, para o primeiro, segundo e terceiro estádios de desenvolvimento dos biótipos, respectivamente. Os tratamentos foram aplicados com pulverizador costal pressurizado por $\mathrm{CO}_{2}$, equipado com pontas do tipo leque Teejet XR 115.02, espaçadas de 0,5 m, volume de calda de $150 \mathrm{~L} \mathrm{ha}^{-1}$ e pressão de trabalho de $1,62 \mathrm{kgf} \mathrm{cm}^{-2}$. No momento da aplicação a temperatura média variou de 21 a $27^{\circ} \mathrm{C}$; a umidade relativa, de 60 a $77 \%$; e a intensidade dos ventos, de 1,2 a $2,5 \mathrm{~km} \mathrm{~h}^{-1}$.

As avaliações de controle foram feitas visualmente, por dois avaliadores, aos 28 DAT (dias após a aplicação dos tratamentos), utilizando escala percentual, em que zero $(0 \%)$ representou ausência de sintomas e 100 $(100 \%)$ a morte completa das plantas (Frans et al., 1986). Após a avaliação, foi realizada a colheita das plantas, para determinar a produção de fitomassa seca da parte aérea. Para isso, o material vegetal foi colhido e submetido à secagem em estufa de circulação forçada de ar a $60{ }^{\circ} \mathrm{C}$, até se obter a massa

Tabela 1 - Identificação do município e das coordenadas do local de coleta dos biótipos de Conyza sumatrensis e a resposta desses biótipos à aplicação dos herbicidas chlorimuron-ethyl e glyphosate, avaliados no primeiro experimento realizado em 2011

\begin{tabular}{|l|l|c|c|c|}
\hline \multicolumn{1}{|c|}{ Código } & \multicolumn{1}{|c|}{ Município } & Coordenadas & Chlorimuron-ethyl & Glyphosate \\
\hline Biótipo 2 & Pontão & $\begin{array}{l}\text { Lat: } 28^{\circ} 00^{\prime} 20.40^{\prime \prime} \mathrm{N} \\
\text { Lon: } 52^{\circ} 45^{\prime} 12.40^{\prime \prime} \mathrm{E}\end{array}$ & $\mathrm{S}$ \\
\hline Biótipo 5 & Carazinho & $\begin{array}{l}\text { Lat: } 28^{\circ} 18^{\prime} 06.51^{\prime \prime} \mathrm{N} \\
\text { Lon: } 52^{\circ} 53^{\prime} 41.31^{\prime \prime} \mathrm{E}\end{array}$ & $\mathrm{S}$ & $\mathrm{R}$ \\
\hline Biótipo 17 & Coqueiros do Sul & $\begin{array}{l}\text { Lat: } 28^{\circ} 07^{\prime} 28.00^{\prime \prime} \mathrm{N} \\
\text { Lon: } 52^{\circ} 42^{\prime} 47.90^{\prime \prime} \mathrm{E}\end{array}$ & $\mathrm{MS}$ & MS \\
\hline Biótipo 20 & Tio Hugo & $\begin{array}{l}\text { Lat: } 28^{\circ} 18^{\prime} 06.51^{\prime \prime} \mathrm{N} \\
\text { Lon: } 52^{\circ} 53^{\prime} 41.31^{\prime \prime} \mathrm{E}\end{array}$ & $\mathrm{MS}$ & MS \\
\hline
\end{tabular}

$\mathrm{S}=$ suscetível, $\mathrm{R}=$ resistente e $\mathrm{MS}=$ menor sensibilidade.

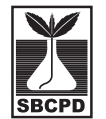


constante, quando foi pesado o material. Transformaram-se os valores de peso em valores percentuais. Os dados obtidos foram analisados quanto à normalidade (teste de Shapiro-Wilk) e, posteriormente, submetidos à análise de variância $(\leq 0,05)$. No caso de ser constatada significância estatística, foi feita análise de regressão para o fator dose, em relação ao estádio de desenvolvimento, para cada biótipo separadamente. A análise de regressão foi realizada com auxílio do programa SigmaPlot 10.0 (Sigmaplot, 2007), ajustandose os dados à equação de regressão sigmoidal do tipo logístico proposto por Streibig (1988):

$$
\mathrm{y}=\mathrm{a} /\left[1+(\mathrm{x} / \mathrm{b})^{\mathrm{c}}\right]
$$

em que: $\mathrm{y}=$ porcentagem de controle e/ou matéria seca da parte aérea; $\mathrm{x}=$ dose do herbicida; e $a, b$ e $c$ são parâmetros da curva, de modo que $a$ é a diferença entre o ponto máximo e mínimo da curva, $b$ é a dose que proporciona a porcentagem de $50 \%$ de resposta da variável e cé a declividade da curva. A partir das equações, determinou-se o $\mathrm{C}_{50}$ e $\mathrm{GR}_{50}$ (dose necessária para obter $50 \%$ de controle e/ou para reduzir $50 \%$ da massa seca da parte aérea da planta), bem como os intervalos de confiança entre os estádios dos biótipos. Por fim, obtevese o fator de sensibilidade (FS), dividindo-se o $\mathrm{C}_{50}$ e $\mathrm{GR}_{50}$ da menor sensibilidade pelo referido valor da maior sensibilidade para cada herbicida nos biótipos.

No estudo da superfície foliar, foram coletadas, no momento da aplicação dos herbicidas, as folhas mais desenvolvidas dos biótipos, nos três estádios de desenvolvimento avaliados. Após isso, as folhas foram fixadas por 48 horas em FAA 70 (formaldeído, ácido acético e etanol 70\%, 5:5:90, v/v) e conservadas em álcool 70\% (Kraus et al., 1998), até a montagem das lâminas para o estudo. As lâminas foram montadas, seccionando-se uma área de aproximadamente $5 \mathrm{~cm}^{2}$ da porção mediana das folhas, utilizando-se o método da impressão da epiderme com cola instantânea (Rodella et al., 1993). Posteriormente, as lâminas foram fotografadas em microscópio Motic BA200, nas objetivas de 10 para os tricomas e 40 para os estômatos, para contagem dos respectivos número e cálculo da densidade. Nas avaliações, foram utilizadas cinco fotos da superficie adaxial, de cada biótipo/ estádio.
Os dados obtidos foram verificados quanto à homogeneidade da variância e, posteriormente, submetidos à ANOVA $(\leq 0,05)$, utilizando o software ASSISTAT 7.6 BETA (Silva \& Azevedo, 2009); quando se verificou efeito significativo, suas médias foram comparadas pelo teste de agrupamento de Scott-Knott $(\mathrm{p}<0,05)$.

\section{RESULTADOS E DISCUSSÃO}

Os resultados na primeira etapa do estudo indicaram que todos os biótipos de buva avaliados foram controlados com a dose máxima de registro do chlorimuron-ethyl $\left(20 \mathrm{~g} \mathrm{ha}^{-1}\right)$, no estádio de desenvolvimento de 3 a 4 folhas, descartando hipótese de resistência ao herbicida. Contudo, observou-se susceptibilidade diferencial entre os biótipos de buva coletadas em doses menores que $20 \mathrm{~g} \mathrm{ha}^{-1} \mathrm{de}$ chlorimuron, indicando diferentes níveis sensibilidade dos biótipos ao herbicida. Com relação ao glyphosate não se observou controle mesmo quando se aplicou o dobro da dose registrada.

Na segunda etapa do trabalho, o resultado da análise de variância para a porcentagem de controle e porcentagem de fitomassa seca da parte aérea indicou que houve interação entre os tratamentos herbicidas, doses e estádios de desenvolvimento em todos os biótipos (dados não apresentados). Os gráficos foram individualizados para cada herbicida nos biótipos. O teste de Shapiro-Wilk confirmou a normalidade dos dados, não sendo necessária a transformação.

As porcentagens de controle e de fitomassa seca da parte aérea para os biótipos de C. sumatrensis 2, 5, 17 e 20, avaliados em três estádios de desenvolvimento, após a aplicação das doses de chlorimuron-ethyl, glyphosate e a associação desses herbicidas, foram ajustadas à equação de regressão sigmoidal do tipo logístico em todas as avaliações. Quanto à porcentagem de controle e à fitomassa seca da parte aérea, os valores do coeficiente de determinação $\left(R^{2}\right)$ variaram de 0,93 a 0,99 e de 0,82 a 0,99 , respectivamente, demonstrando ajuste satisfatório dos dados ao modelo (Tabelas 2 e 3). A partir das equações, foram calculados os valores de $\mathrm{C}_{50}, \mathrm{GR}_{50}$ e o FS, sendo este calculado a partir dos valores de $\mathrm{C}_{50}$ e 
Tabela 2 - Percentual de controle pelas equações de regressões (Y) em função das doses dos herbicidas (X) (HERB), estádios de controle (EST), valores de $\mathrm{C}_{50}$ com intervalos de confiança (IC, 95\%) e fator de sensibilidade (FS) em quatro biótipos de C. sumatrensis, em resposta à aplicação de doses dos herbicidas chlorimuron-ethyl (CHLOR) e glyphosate (GLYPH) e à associação deles (ASSOC), avaliados aos 28 dias após o tratamento (DAT)

\begin{tabular}{|c|c|c|c|c|c|c|c|}
\hline & \multirow{2}{*}{$\mathrm{HERB}^{\underline{1}}$} & \multirow{2}{*}{$\mathrm{EST}^{2 /}$} & \multirow{2}{*}{ Equações de Regressão ${ }^{3 /}$} & \multirow{2}{*}{$\mathrm{R}^{2}$} & \multicolumn{2}{|c|}{$\mathrm{C}_{50}{ }^{4 /}$} & \multirow{2}{*}{$\mathrm{FS}^{5 /}$} \\
\hline & & & & & $\% \mathrm{D} \mathrm{R} \mathrm{ha}^{-1} \underline{6}$ & $\mathrm{IC}$ & \\
\hline \multirow{9}{*}{$\begin{array}{l}N \\
0 \\
\vdots \\
\vdots \\
0\end{array}$} & \multirow{3}{*}{ CHLOR } & 1 & $Y=100 /\left[1+(X / 4,99)^{-6,52}\right]$ & 0,99 & 4,99 & $4,1-5,9$ & - \\
\hline & & 2 & $\mathrm{Y}=150,52 /\left[1+(\mathrm{X} / 148,16)^{-0,41}\right]$ & 0,99 & 26,79 & $22,4-31,1$ & 5,40 \\
\hline & & 3 & $\mathrm{Y}=102,04 /\left[1+(\mathrm{X} / 50,91)^{-0,76}\right]$ & 0,97 & 48,32 & $39,9-56,7$ & 9,70 \\
\hline & \multirow{3}{*}{ GLYPH } & 1 & $\mathrm{Y}=102,33 /\left[1+(\mathrm{X} / 24,75)^{-1,27}\right]$ & 0,99 & 23,88 & $21-27$ & - \\
\hline & & 2 & $\mathrm{Y}=104 /\left[1+(\mathrm{X} / 32,85)^{-1,08}\right]$ & 0,97 & 30,61 & $23-39$ & NS \\
\hline & & 3 & $\mathrm{Y}=96,75 /\left[1+(\mathrm{X} / 33,73)^{-1,10}\right]$ & 0,99 & 33,85 & $30-41$ & 1,40 \\
\hline & \multirow{3}{*}{ ASSOC } & 1 & $\mathrm{Y}=113,13 /\left[1+(\mathrm{X} / 2,74)^{-0,44}\right]$ & 0,99 & 1,61 & $1,6-1,62$ & - \\
\hline & & 2 & $\mathrm{Y}=100,46 /\left[1+(\mathrm{X} / 3,79)^{-5,01}\right]$ & 0,99 & 3,79 & $1,7-5,8$ & 2,35 \\
\hline & & 3 & $\mathrm{Y}=104,71 /\left[1+(\mathrm{X} / 25,88)^{-0,97}\right]$ & 0,98 & 23,58 & $12,1-35$ & 14,60 \\
\hline \multirow{9}{*}{$\begin{array}{l}n \\
0 \\
0 \\
0 \\
0\end{array}$} & \multirow{3}{*}{ CHLOR } & 1 & $\mathrm{Y}=100 /\left[1+(\mathrm{X} / 4,05)^{-25,07}\right]$ & 0,99 & 4,05 & $2-6,1$ & - \\
\hline & & 2 & $\mathrm{Y}=96,97 /\left[1+(\mathrm{X} / 20,4)^{-0,96}\right]$ & 0,95 & 21,78 & $13,6-30$ & 5,38 \\
\hline & & 3 & $\mathrm{Y}=90,73 /\left[1+(\mathrm{X} / 27,02)^{-0,88}\right]$ & 0,98 & 34,09 & $30,9-37,3$ & 8,42 \\
\hline & \multirow{3}{*}{ GLYPH } & 1 & $\mathrm{Y}=61,49 /\left[1+(\mathrm{X} / 53,29)^{-0,88}\right]$ & 0,98 & 281,60 & $276-287$ & - \\
\hline & & 2 & $\mathrm{Y}=56,24 /\left[1+(\mathrm{X} / 69,67)^{-1,26}\right]$ & 0,99 & 362,30 & $358-367$ & 1,29 \\
\hline & & 3 & $\mathrm{Y}=61,09 /\left[1+(\mathrm{X} / 104,36)^{-1,09}\right]$ & 0,99 & IFG & - & - \\
\hline & \multirow{3}{*}{ ASSOC } & 1 & $\mathrm{Y}=100 /\left[1+(\mathrm{X} / 2,37)^{-5,69}\right]$ & 0,99 & 2,37 & $2,36-2,38$ & - \\
\hline & & 2 & $Y=107,47 /\left[1+(X / 7,66)^{-0,78}\right]$ & 0,99 & 6,41 & $5,2-7,6$ & 2,70 \\
\hline & & 3 & $\mathrm{Y}=100,8 /\left[1+(\mathrm{X} / 39,83)^{-1,23}\right]$ & 0,99 & 39,17 & $33,5-44,8$ & 16,50 \\
\hline \multirow{9}{*}{$\begin{array}{l}= \\
0 \\
0 \\
0 \\
0 \\
0\end{array}$} & \multirow{3}{*}{ CHLOR } & 1 & $\mathrm{Y}=102,84 /\left[1+(\mathrm{X} / 4,7)^{-1,08}\right]$ & 0,98 & 4,47 & $3,5-5,8$ & - \\
\hline & & 2 & $\mathrm{Y}=83,86 /\left[1+(\mathrm{X} / 48,53)^{-0,8}\right]$ & 0,98 & 79,16 & $74,4-83,9$ & 17,10 \\
\hline & & 3 & $\mathrm{Y}=76,01 /\left[1+(\mathrm{X} / 48,29)^{-1,02}\right]$ & 0,98 & 91,76 & $85,1-98,4$ & 20,50 \\
\hline & \multirow{3}{*}{ GLYPH } & 1 & $\mathrm{Y}=136,95 /\left[1+(\mathrm{X} / 90,52)^{-0,73}\right]$ & 0,98 & 42,63 & $36,1-49,1$ & - \\
\hline & & 2 & $\mathrm{Y}=129,27 /\left[1+(\mathrm{X} / 101,14)^{-0,77}\right]$ & 0,97 & 55,66 & $50,2-61,2$ & 1,30 \\
\hline & & 3 & $\mathrm{Y}=90,84 /\left[1+(\mathrm{X} / 56,03)^{-1,07}\right]$ & 0,99 & 67,69 & $61,6-7,8$ & 1,60 \\
\hline & \multirow{3}{*}{ ASSOC } & 1 & $\mathrm{Y}=100,23 /\left[1+(\mathrm{X} / 4,88)^{-2,69}\right]$ & 0,99 & 4,88 & $4,5-5$ & - \\
\hline & & 2 & $\mathrm{Y}=105,98 /\left[1+(\mathrm{X} / 12,04)^{-1,09}\right]$ & 0,98 & 10,86 & $9-12,75$ & 2,20 \\
\hline & & 3 & $Y=65,68 /\left[1+(X / 53,58)^{-1,08}\right]$ & 0,99 & 157,37 & $146-169$ & 32,20 \\
\hline \multirow{9}{*}{ 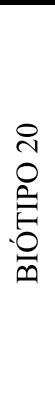 } & \multirow{3}{*}{ CHLOR } & 1 & $\mathrm{Y}=100,12 /\left[1+(\mathrm{X} / 3,61)^{-2,62}\right]$ & 0,99 & 3,61 & $3,1-4,2$ & - \\
\hline & & 2 & $\mathrm{Y}=84,63 /\left[1+(\mathrm{X} / 20,26)^{-1,18}\right]$ & 0,93 & 27,68 & $21,8-33,6$ & 4,90 \\
\hline & & 3 & $\mathrm{Y}=83,08 /\left[1+(\mathrm{X} / 36,84)^{-1,02}\right]$ & 0,97 & 55,21 & $46,5-64$ & 15,30 \\
\hline & \multirow{3}{*}{ GLYPH } & 1 & $\mathrm{Y}=756,39 /\left[1+(\mathrm{X} / 36.99)^{-0,43}\right]$ & 0,96 & 80,41 & $77-83$ & - \\
\hline & & 2 & $\mathrm{Y}=116,51 /\left[1+(\mathrm{X} / 166,54)^{-0,73}\right]$ & 0,98 & 112,96 & $106-120$ & 1,40 \\
\hline & & 3 & $\mathrm{Y}=81,24 /\left[1+(\mathrm{X} / 85,09)^{-0,96}\right]$ & 0,99 & 139,22 & $134-144$ & 1,70 \\
\hline & \multirow{3}{*}{ ASSOC } & 1 & $\mathrm{Y}=104,38 /\left[1+(\mathrm{X} / 5,57)^{-0,18}\right]$ & 0,97 & 3,50 & $0,7-6,3$ & - \\
\hline & & 2 & $\mathrm{Y}=105,39 /\left[1+(\mathrm{X} / 11,32)^{-1,02}\right]$ & 0,98 & 10,24 & $8,7-11,8$ & 2,90 \\
\hline & & 3 & $\mathrm{Y}=78,04 /\left[1+(\mathrm{X} / 42,08)^{-0,99}\right]$ & 0,99 & 75,28 & $68,5-82,1$ & 21,50 \\
\hline
\end{tabular}

1/ Herbicidas: chlorimuron-ethyl, glyphosate e associação de chlorimuron-ethyl e glyphosate, sendo oito porcentagens das doses dos herbicidas: $0,6,25 \% \mathrm{D}, 12,5 \% \mathrm{D}, 25 \% \mathrm{D}, 50 \% \mathrm{D}, 100 \% \mathrm{D}, 200 \% \mathrm{D}$ e $400 \% \mathrm{D}$, em que $\mathrm{D}$ foi a dose de registro dos herbicidas chlorimuronethyl, $20 \mathrm{~g} \mathrm{ha}^{-1}$, e glyphosate, $720 \mathrm{~g}$ e.a. ha ${ }^{-1} ; \underline{2}$ Estádios de desenvolvimento na aplicação dos herbicidas: $1=$ altura de $0,5-1 \mathrm{~cm}$ e $3-$ 4 folhas, $2=$ altura de $1-2 \mathrm{~cm}$ e $6-7$ folhas e $3=$ altura de $10-12 \mathrm{~cm}$ e $12-14$ folhas, sendo folhas completamente expandidas; ${ }^{3 /} \mathrm{Y}=\mathrm{a} /[1$ $+(\mathrm{X} / \mathrm{b}) \mathrm{c}] ;{ }^{4 /} \mathrm{C}_{50}=$ dose necessária para obter $50 \%$ de controle; ${ }^{5} /$ Fator de sensibilidade aos herbicidas pelos biótipos de Conyza sumatrensis, obtido da divisão do $\mathrm{C}_{50}$ dos biótipos em relação ao estádio de maior sensibilidade do biótipo para cada um dos herbicidas (primeiro estádio); 6/ Porcentagem da dose recomendada por hectare; Ns Para cada herbicida, a sobreposição do intervalo de confiança do estádio de maior sensibilidade do biótipo indica que não ocorreu diferença significativa entre $\mathrm{C}_{50}$ para os estádios avaliados; ${ }^{\mathrm{IFG}}$ Valor fora do intervalo $(\mathrm{X})$ do gráfico avaliado. 
Tabela 3 - Percentual de fitomassa seca nas equações de regressões (Y) em função de doses dos herbicidas (X) (HERB), estádios de controle (EST), valores de $\mathrm{C}_{50}$ com intervalos de confiança (IC, 95\%) e fator de sensibilidade (FS) em quatro biótipos de C. sumatrensis, em resposta à aplicação de doses crescentes dos herbicidas chlorimuron-ethyl (CHLOR) e glyphosate (GLYPH) e à associação deles (ASSOC), avaliados aos 28 dias após o tratamento (DAT)

\begin{tabular}{|c|c|c|c|c|c|c|c|}
\hline & \multirow{2}{*}{$\mathrm{HERB}^{1 /}$} & \multirow{2}{*}{$\mathrm{EST}^{2 /}$} & \multirow{2}{*}{ Equações de Regressão ${ }^{3 /}$} & \multirow{2}{*}{$\mathrm{R}^{2}$} & \multicolumn{2}{|c|}{$\mathrm{GR}_{50}{ }^{4 /}$} & \multirow{2}{*}{$\mathrm{FS}^{5 /}$} \\
\hline & & & & & $\%$ Dose ha ${ }^{-1}$ & $95 \%$ IC & \\
\hline \multirow{9}{*}{ 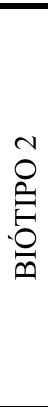 } & \multirow{3}{*}{ CHLOR } & 1 & $\mathrm{Y}=100 /\left[1+(\mathrm{X} / 1)^{0,12}\right]$ & 0,99 & 1,00 & $0,9-1,1$ & - \\
\hline & & 2 & $\mathrm{Y}=100,01 /\left[1+(\mathrm{X} / 1,27)^{0,22}\right]$ & 0,97 & 1,27 & $0,8-1,8$ & NS \\
\hline & & 3 & $\mathrm{Y}=100,13 /\left[1+(\mathrm{X} / 28,2)^{0,0,34}\right]$ & 0,98 & 28,41 & $21,2-35,6$ & 28,40 \\
\hline & \multirow{3}{*}{ GLYPH } & 1 & $\mathrm{Y}=100 /\left[1+(\mathrm{X} / 4,76)^{0,47}\right]$ & 0,98 & 4,76 & $3,5-6,0$ & - \\
\hline & & 2 & $\mathrm{Y}=100,1 /\left[1+(\mathrm{X} / 6,01)^{0,36}\right]$ & 0,97 & 6,01 & $3,4-8,6$ & NS \\
\hline & & 3 & $\mathrm{Y}=100,51 /\left[1+(\mathrm{X} / 53,93)^{0,38}\right]$ & 0,92 & 55,39 & $43,9-66,8$ & 11,60 \\
\hline & \multirow{3}{*}{ ASSOC } & 1 & $\mathrm{Y}=100 /\left[1+(\mathrm{X} / 0,88)^{0,11}\right]$ & 0,99 & 0,88 & $0,84-0,92$ & - \\
\hline & & 2 & $\mathrm{Y}=100,01 /\left[1+(\mathrm{X} / 1,14)^{0,22}\right]$ & 0,99 & 1,14 & $0,93-1,3$ & 1,30 \\
\hline & & 3 & $\mathrm{Y}=100,58 /\left[1+(\mathrm{X} / 13,47)^{0,53}\right]$ & 0,98 & 13,76 & $10,6-16,9$ & 15,60 \\
\hline \multirow{9}{*}{$\begin{array}{l}n \\
0 \\
0 \\
0 \\
0\end{array}$} & \multirow{3}{*}{ CHLOR } & 1 & $\mathrm{Y}=100 /\left[1+(\mathrm{X} / 1,34)^{0,17}\right]$ & 0,99 & 1,34 & $1,1-1,6$ & - \\
\hline & & 2 & $\mathrm{Y}=99,97 /\left[1+(\mathrm{X} / 1,89)^{0,24}\right]$ & 0,95 & 1,89 & $1,4-2,3$ & NS \\
\hline & & 3 & $\mathrm{Y}=101,83 /\left[1+(\mathrm{X} / 89,92)^{0,54}\right]$ & 0,95 & 89,92 & $85,5-106,7$ & 67,10 \\
\hline & \multirow{3}{*}{ GLYPH } & 1 & $\mathrm{Y}=102,35 /\left[1+(\mathrm{X} / 18,72)^{0,73}\right]$ & 0,87 & 19,94 & $12-28$ & - \\
\hline & & 2 & $\mathrm{Y}=102,02 /\left[1+(\mathrm{X} / 124,13)^{0,54}\right]$ & 0,82 & 133,49 & $114-153$ & 6,69 \\
\hline & & 3 & $\mathrm{Y}=100,75 /\left[1+(\mathrm{X} / 7022)^{0,39}\right]$ & 0,87 & IFG & - & - \\
\hline & \multirow{3}{*}{ ASSOC } & 1 & $\mathrm{Y}=100 /\left[1+(\mathrm{X} / 0,9)^{0,14}\right]$ & 0,99 & 0,90 & $0,7-1,1$ & - \\
\hline & & 2 & $\mathrm{Y}=100,01 /\left[1+(\mathrm{X} / 1,16)^{0,2}\right]$ & 0,94 & 1,16 & $0,8-1,6$ & NS \\
\hline & & 3 & $\mathrm{Y}=100,67 /\left[1+(\mathrm{X} / 24,51)^{0,44}\right]$ & 0,97 & 25,25 & $18,9-31,6$ & 28,05 \\
\hline \multirow{9}{*}{ 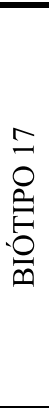 } & \multirow{3}{*}{ CHLOR } & 1 & $\mathrm{Y}=100,01 /\left[1+(\mathrm{X} / 1,06)^{0,14}\right]$ & 0,93 & 1,06 & $0,8-1,3$ & - \\
\hline & & 2 & $\mathrm{Y}=100,16 /\left[1+(\mathrm{X} / 16,61)^{0,32}\right]$ & 0,82 & 16,77 & $13,1-20,4$ & 15,80 \\
\hline & & 3 & $\mathrm{Y}=102,65 /\left[1+(\mathrm{X} / 148,62)^{0,48}\right]$ & 0,91 & 165,32 & $153-177$ & 155,90 \\
\hline & \multirow{3}{*}{ GLYPH } & 1 & $\mathrm{Y}=100,12 /\left[1+(\mathrm{X} / 6,01)^{0,48}\right]$ & 0,96 & 6,03 & $3,5-8,5$ & - \\
\hline & & 2 & $\mathrm{Y}=100,87 /\left[1+(\mathrm{X} / 61,5)^{0,52}\right]$ & 0,97 & 63,56 & $55,9-71,2$ & 10,50 \\
\hline & & 3 & $\mathrm{Y}=101,14 /\left[1+(\mathrm{X} / 108,2)^{0,61}\right]$ & 0,95 & 112,25 & $102-123$ & 18,60 \\
\hline & \multirow{3}{*}{ ASSOC } & 1 & $\mathrm{Y}=100,01 /\left[1+(\mathrm{X} / 0,98)^{0,26}\right]$ & 0,99 & 0,98 & $0,7-1,3$ & - \\
\hline & & 2 & $\mathrm{Y}=100 /\left[1+(\mathrm{X} / 1,34)^{0,19}\right]$ & 0,99 & 1,34 & $1,0-1,5$ & NS \\
\hline & & 3 & $\mathrm{Y}=100,24 /\left[1+(\mathrm{X} / 105,14)^{0,51}\right]$ & 0,96 & 106,12 & $80,8-131,5$ & 108,30 \\
\hline \multirow{9}{*}{ 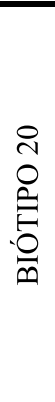 } & \multirow{3}{*}{ CHLOR } & 1 & $Y=100 /\left[1+(X / 0,93)^{0,16}\right]$ & 0,99 & 0,93 & $0,7-1,2$ & - \\
\hline & & 2 & $\mathrm{Y}=100,04 /\left[1+(\mathrm{X} / 7,66)^{0,3}\right]$ & 0,99 & 7,68 & $6,0-9,4$ & 8,30 \\
\hline & & 3 & $\mathrm{Y}=101,47 /\left[1+(\mathrm{X} / 38,52)^{0,46}\right]$ & 0,93 & 41,04 & $28,3-53,7$ & 44,10 \\
\hline & \multirow{3}{*}{ GLYPH } & 1 & $\mathrm{Y}=100,25 /\left[1+(\mathrm{X} / 8,74)^{0,54}\right]$ & 0,98 & 8,82 & $6,7-11,0$ & - \\
\hline & & 2 & $\mathrm{Y}=100,59 /\left[1+(\mathrm{X} / 52,31)^{0,52}\right]$ & 0,99 & 53,49 & $48,0-58,9$ & 6,10 \\
\hline & & 3 & $\mathrm{Y}=100,5 /\left[1+(\mathrm{X} / 152,83)^{0,44}\right]$ & 0,97 & 156,3 & $145-163$ & 17,70 \\
\hline & \multirow{3}{*}{ ASSOC } & 1 & $\mathrm{Y}=100 /\left[1+(\mathrm{X} / 0,72)^{0,16}\right]$ & 0,99 & 0,72 & $0,66-0,78$ & - \\
\hline & & 2 & $\mathrm{Y}=100,01 /\left[1+(\mathrm{X} / 2,2)^{0,21}\right]$ & 0,85 & 2,20 & $1,3-3,1$ & 3,05 \\
\hline & & 3 & $\mathrm{Y}=99,87 /\left[1+(\mathrm{X} / 47,85)^{0,52}\right]$ & 0,98 & 47,62 & $40,3-54,9$ & 66,10 \\
\hline
\end{tabular}

${ }_{1 /}^{1}$ Herbicidas: chlorimuron-ethyl, glyphosate e associação de chlorimuron-ethyl e glyphosate, sendo oito porcentagens das doses dos herbicidas: $0,6,25 \% \mathrm{D}, 12,5 \% \mathrm{D}, 25 \% \mathrm{D}, 50 \% \mathrm{D}, 100 \% \mathrm{D}, 200 \% \mathrm{D}$ e $400 \% \mathrm{D}$, em que $\mathrm{D}$ foi a dose de registro dos herbicidas chlorimuronethyl, $20 \mathrm{~g} \mathrm{ha}^{-1}$, e glyphosate, $720 \mathrm{~g}$ e.a. ha ${ }^{-1} ; \underline{2}$ Estádios de desenvolvimento na aplicação dos herbicidas: $1=$ altura de $0,5-1 \mathrm{~cm}$ e $3-$ 4 folhas, $2=$ altura de $1-2 \mathrm{~cm}$ e $6-7$ folhas e $3=$ altura de $10-12 \mathrm{~cm}$ e $12-14$ folhas, sendo folhas completamente expandidas; ${ }^{3} / \mathrm{Y}=\mathrm{a} /[1$ $\left.+(\mathrm{X} / \mathrm{b})^{\mathrm{c}}\right] ;{ }^{4 /} \mathrm{GR}_{50}=$ dose necessária para obter redução de $50 \%$ na fitomassa seca da parte aérea do biótipo ${ }^{5 /}$ Fator de sensibilidade aos herbicidas pelos biótipos de Conyza sumatrensis, obtido da divisão do $\mathrm{GR}_{50}$ dos biótipos em relação ao estádio de maior sensibilidade do biótipo para cada um dos herbicidas (primeiro estádio); ${ }^{6 /}$ Porcentagem da dose recomendada por hectare; NS Para cada herbicida, a sobreposição do intervalo de confiança do estádio de maior sensibilidade do biótipo indica que não ocorreu diferença significativa entre $\mathrm{GR}_{50}$ para os estádios avaliados; ${ }^{\mathrm{IFG}}$ Valor fora do intervalo (X) do gráfico avaliado. 
$\mathrm{GR}_{50}$, para cada herbicida e estádio de desenvolvimento, entre os biótipos avaliados (Tabelas 2 e 3).

As equações formadas com os valores de porcentagem de controle nos biótipos 2, 5, 17 e 20 de C. sumatrensis comprovam a existência de níveis de sensibilidade de acordo com o desenvolvimento dos biótipos, o que é evidenciado pelo aumento dos valores de $\mathrm{C}_{50}$, $\mathrm{GR}_{50}$ e FS, para todos os herbicidas avaliados (Tabelas 2 e 3). A porcentagem de fitomassa seca da parte aérea mostrou comportamento similar ao de controle, mas com valores decrescentes com o aumento nas doses dos herbicidas, em todos os biótipos avaliados (Figuras 1, 2, 3 e 4).

O biótipo 2, no primeiro estádio, foi controlado usando-se os tratamentos chlorimuron-ethyl e glyphosate nas doses de $12,5 \%\left(2,5 \mathrm{~g} \mathrm{ha}^{-1}\right)$ e de $100 \%$ (720 g e.a. ha-1), respectivamente, e, na associação, na menor dose $6,25 \%(1,25 \mathrm{~g}+45 \mathrm{~g}$ e.a. ha-1) (Figura $1 \mathrm{~A}$, B, C). No entanto, no segundo estádio, o biótipo 2 apresentou controle de $90 \%$ para a maior dose de chlorimuron (400\% ou $80 \mathrm{~g} \mathrm{ha}^{-1}$ ), de $100 \%$ para glyphosate aplicado isoladamente e, para associação, na dose de $200 \%$ $(40 \mathrm{~g}+1.440$ g e.a. ha-1) (Figura 1A, B, C). No terceiro estádio do biótipo, o controle com chlorimuron foi de aproximadamente $80 \%$, e o de glyphosate, de 90\%, na maior dose utilizada $\left(400 \%\right.$ ou $80 \mathrm{~g}$ e $2.880 \mathrm{~g}$ e.a. ha $\left.\mathrm{ha}^{-1}\right)$ (Figura 1A, B). Já a associação dos herbicidas proporcionou $100 \%$ de controle na maior dose (400\% ou 80 g e 2.880 g e.a. ha ${ }^{-1}$ ) (Figura 1C). Esses resultados evidenciam que a sensibilidade do biótipo 2 ao chlorimuron, ao glyphosate e à associação destes diminuiu com o seu desenvolvimento; para o chlorimuron, a dose de $12,5 \mathrm{~g} \mathrm{ha}^{-1}$ proporcionou controle de $100 \%$ do biótipo no primeiro estádio e a máxima dose $\left(80 \mathrm{~g} \mathrm{ha}^{-1}\right)$ proporcionou controles de $90 \%$ e de $80 \%$ no segundo e terceiro estádios, respectivamente.

Com relação aos intervalos de confiança (IC), tendo como referência a ausência de sobreposição do IC do estádio de maior sensibilidade (primeiro estádio) em relação ao IC do de menor sensibilidade (terceiro estádio), foi possivel calcular o fator de sensibilidade (FS) com os valores do $\mathrm{C}_{50}$ e do $\mathrm{GR}_{50}$ no biótipo 2 para todos os herbicidas. O FS calculado com os valores do $\mathrm{C}_{50}$, para o biótipo 2 , com o chlorimuron foi de 5,4 do primeiro para o segundo estádio e de 9,7 do primeiro para o terceiro estádio (Tabela 2). Já o FS do biótipo calculado com os valores do $\mathrm{GR}_{50}$ não diferiu do primeiro para o segundo estádio e foi de 28,4 do primeiro para o terceiro estádio (Tabela 3). Quanto ao glyphosate, o FS do biótipo 2 não diferiu do primeiro para o segundo estádio e foi de 1,4 do primeiro para o terceiro estádio, para os valores do $\mathrm{C}_{50}$ (Tabela 2). Já o FS do biótipo calculado com os valores do $\mathrm{GR}_{50}$ não diferiu do primeiro para o segundo estádio e foi de 11,6 do primeiro para o terceiro estádio (Tabela 3). A associação de chlorimuron + glyphosate apresentou FS de 2,35 no biótipo 2 do primeiro para o segundo estádio e de 14,6 do primeiro para o terceiro, para os valores do $\mathrm{C}_{50}$ (Tabela 2). Já o FS do biótipo calculado com os valores do $\mathrm{GR}_{50}$ foi de 1,3 do primeiro para o segundo estádio e de 15,6 do primeiro para o terceiro estádio (Tabela 3). Esses resultados indicam que a sensibilidade do biótipo 2 , aos herbicidas e à associação avaliada, está relacionada ao estádio de desenvolvimento: quanto mais avançado o estádio, menor a sensibilidade.

Já o biótipo 5, no primeiro estádio, foi controlado com chlorimuron-ethyl na menor dose $\left(6,25 \%\right.$ ou $\left.1,25 \mathrm{~g} \mathrm{ha}^{-1}\right)$ e, na associação de chlorimuron + glyphosate, usando-se a dose de 12,5\% (2,5 g + 90 g e.a. ha-1) (Figura 2A, C). Entretanto, no segundo estádio, o biótipo 5 demonstrou controle de $90 \%$ na maior dose (400\% ou $80 \mathrm{~g} \mathrm{ha}^{-1}$ ) de chlorimuron e, na associação, foi controlado com uso de $100 \%$ da dose (20 g e 720 g e.a. ha ${ }^{-1}$ ) (Figura 2A, C). Contudo, no terceiro estádio do biótipo, o controle com chlorimuron foi de aproximadamente $80 \%$ na maior dose $\left(400 \%\right.$ ou $\left.80 \mathrm{~g} \mathrm{ha}^{-1}\right)$ e, na associação, apresentou $90 \%$ de controle, na maior dose $\left(400 \%\right.$ ou $80 \mathrm{~g}+2.880$ g e.a. ha $\left.{ }^{-1}\right)$ (Figura 2C).

Para o biótipo 5, foi possivel calcular o fator de sensibilidade (FS) com os valores do $\mathrm{C}_{50}$ e do $\mathrm{GR}_{50}$ para todos os herbicidas. O FS calculado com os valores do $\mathrm{C}_{50}$, para o biótipo 5 , com o chlorimuron foi de 5,38 do primeiro para o segundo estádio e de 8,42 do primeiro para o terceiro estádio (Tabela 2). Já o FS calculado com os valores do $\mathrm{GR}_{50}$ do biótipo não diferiu do primeiro para o segundo estádio e foi de 67,1 

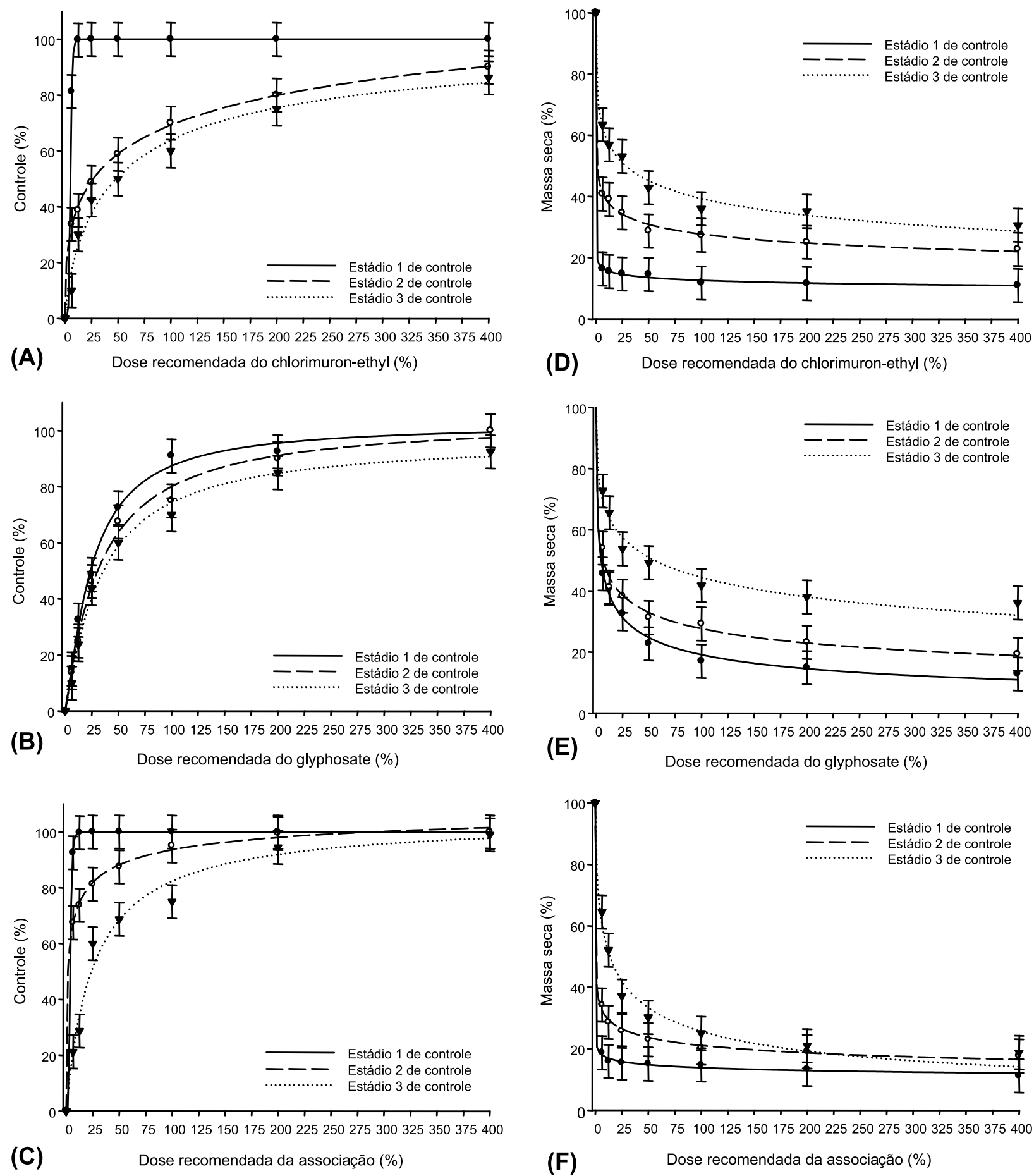

Figura 1 - Percentual de controle e fitomassa seca da parte aérea no biótipo 2 de $C$. sumatrensis aos 28 dias após aplicação de doses dos herbicidas chlorimuron-ethyl (A e D) e glyphosate (B e E) e da associação deles (C e F). As barras verticais representam $95 \%$ de intervalo de confiança.

do primeiro para o terceiro estádio (Tabela 3). $\mathrm{Na}$ associação de chlorimuron + glyphosate, o biótipo 5 apresentou FS de 2,7 do primeiro para o segundo estádio e de 16,5 do primeiro para o terceiro, para os valores do $\mathrm{C}_{50}$ (Tabela 2). O FS do biótipo calculado com os valores do $\mathrm{GR}_{50}$ não diferiu do primeiro para o segundo estádio e foi de 28,05 do primeiro para o 

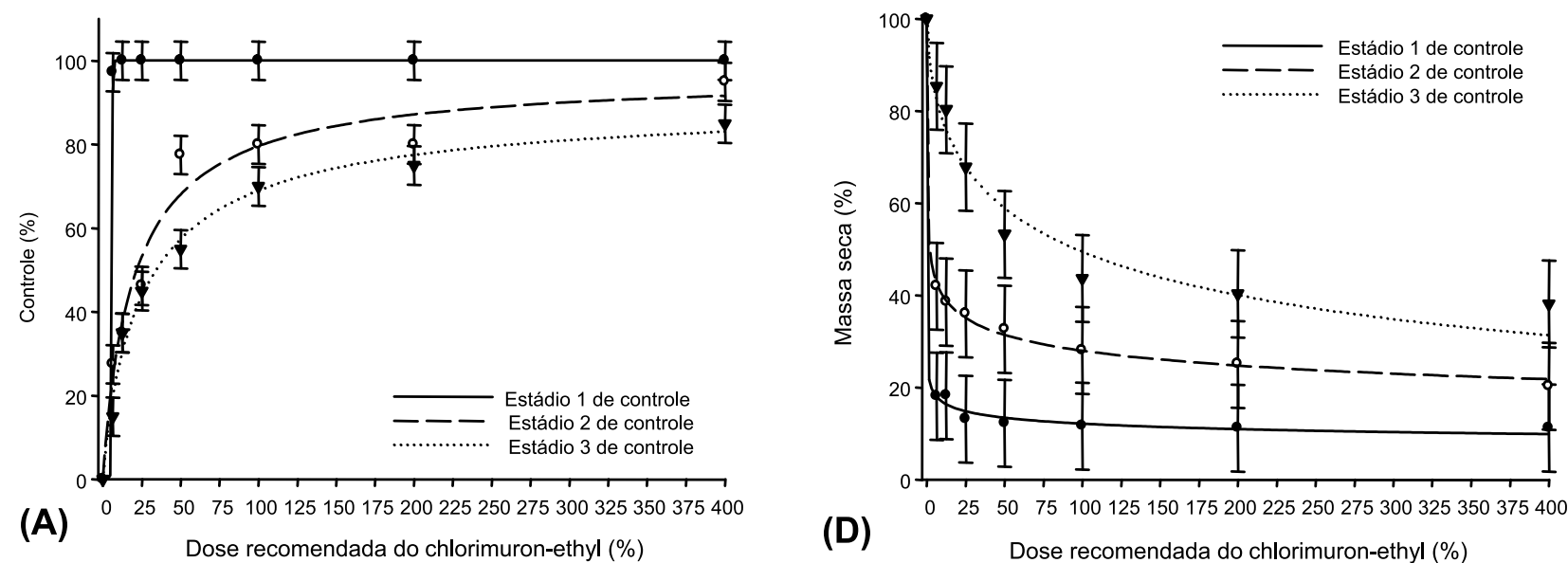

(D)

$0 \quad 255075100125150175200225250275300325350375400$

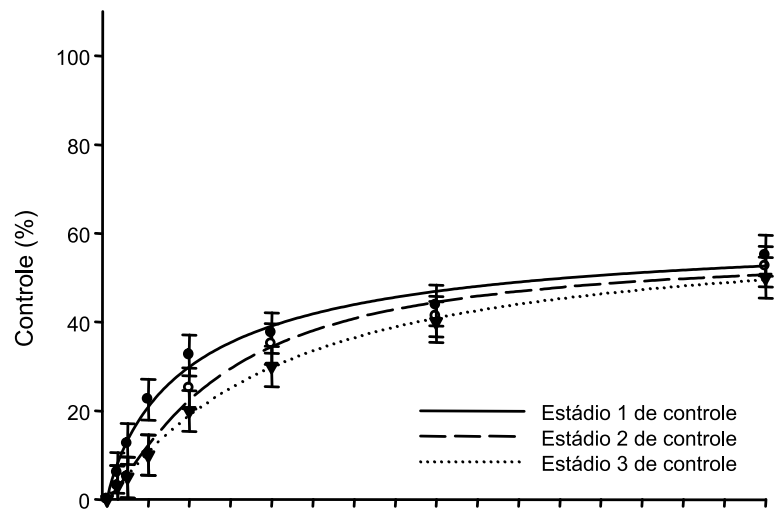

(B)

$0 \quad 255075100125150175200225250275300325350375400$ Dose recomendada do glyphosate (\%)
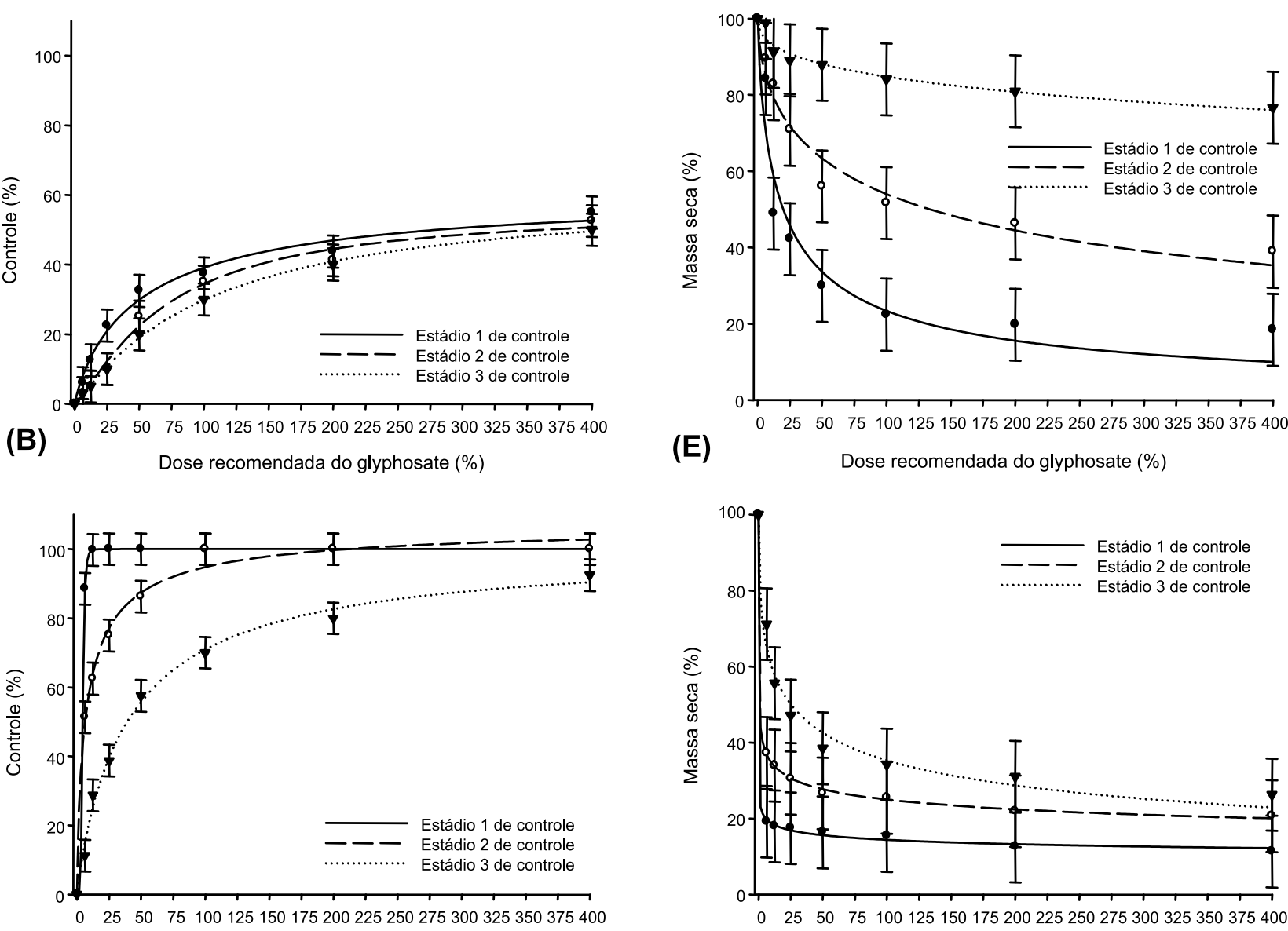

(C)

Dose recomendada da associação (\%)

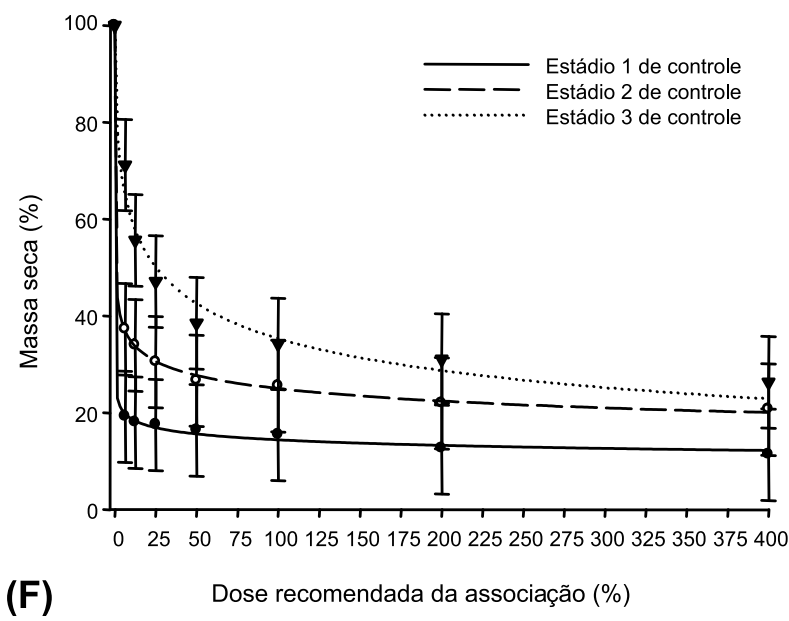

Figura 2 - Percentual de controle e fitomassa seca da parte aérea no biótipo 5 de C. sumatrensis aos 28 dias após aplicação de doses dos herbicidas chlorimuron-ethyl (A e D) e glyphosate (B e E) e da associação deles (C e F). As barras verticais representam $95 \%$ de intervalo de confiança.

terceiro estádio (Tabela 3). Esse resultado evidencia a redução da sensibilidade do biótipo 5 ao chlorimuron em estádios mais avançados de desenvolvimento. O aumento nos valores do $\mathrm{C}_{50}$ e $\mathrm{GR}_{50}$ e os níveis de sensibilidade calculados a partir deles comprovam a menor sensibilidade no terceiro estádio de desenvolvimento ao chlorimuron (Tabelas 2 e 4). 
A aplicação isolada do glyphosate no biótipo 5 evidenciou controle de aproximadamente $50 \%$ na maior dose $\left(400 \%\right.$ ou 2.880 g e.a. ha $\left.{ }^{-1}\right)$ nos três estádios avaliados, demonstrando
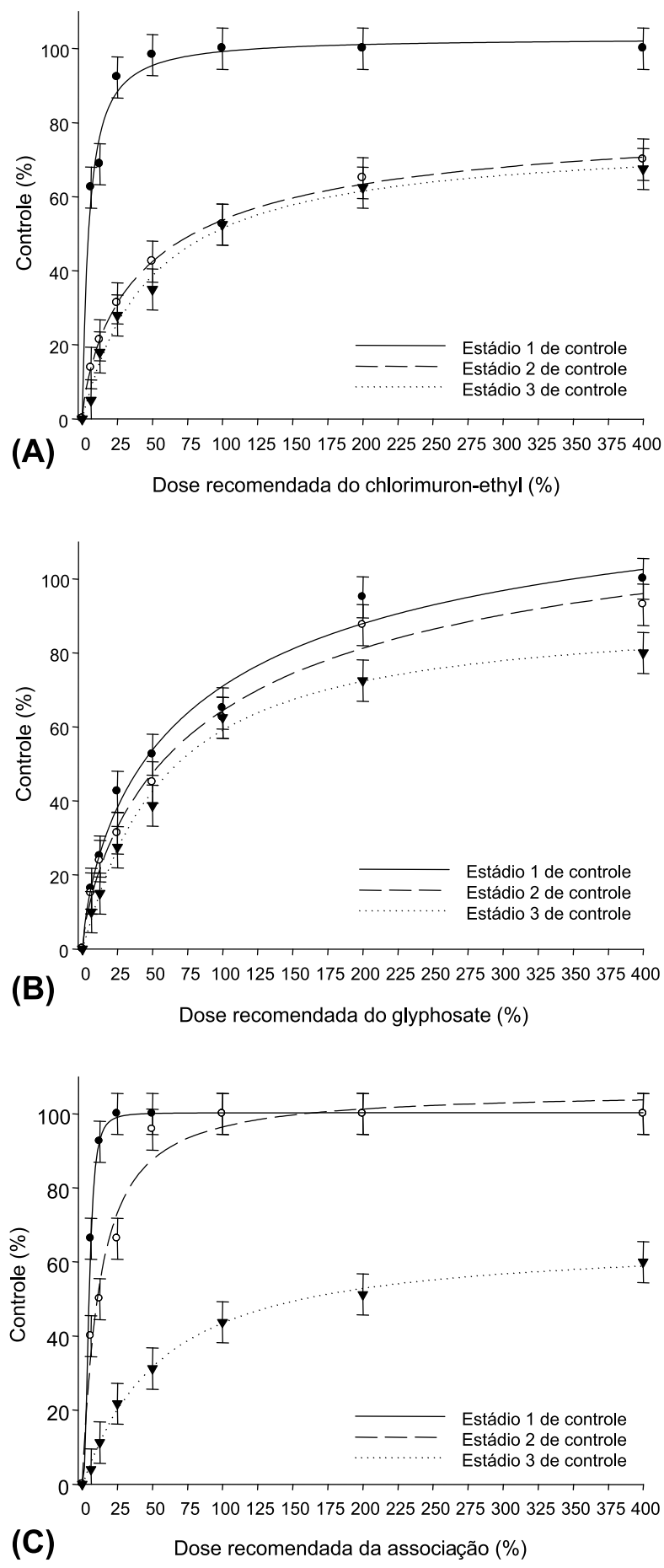

sua resistência ao herbicida (Figura 2B). Ressalta-se que a dose considerada para que uma planta seja resistente a esse herbicida é de 2.160 g e.a. ha-1 (AGROFIT, 2013), inferior
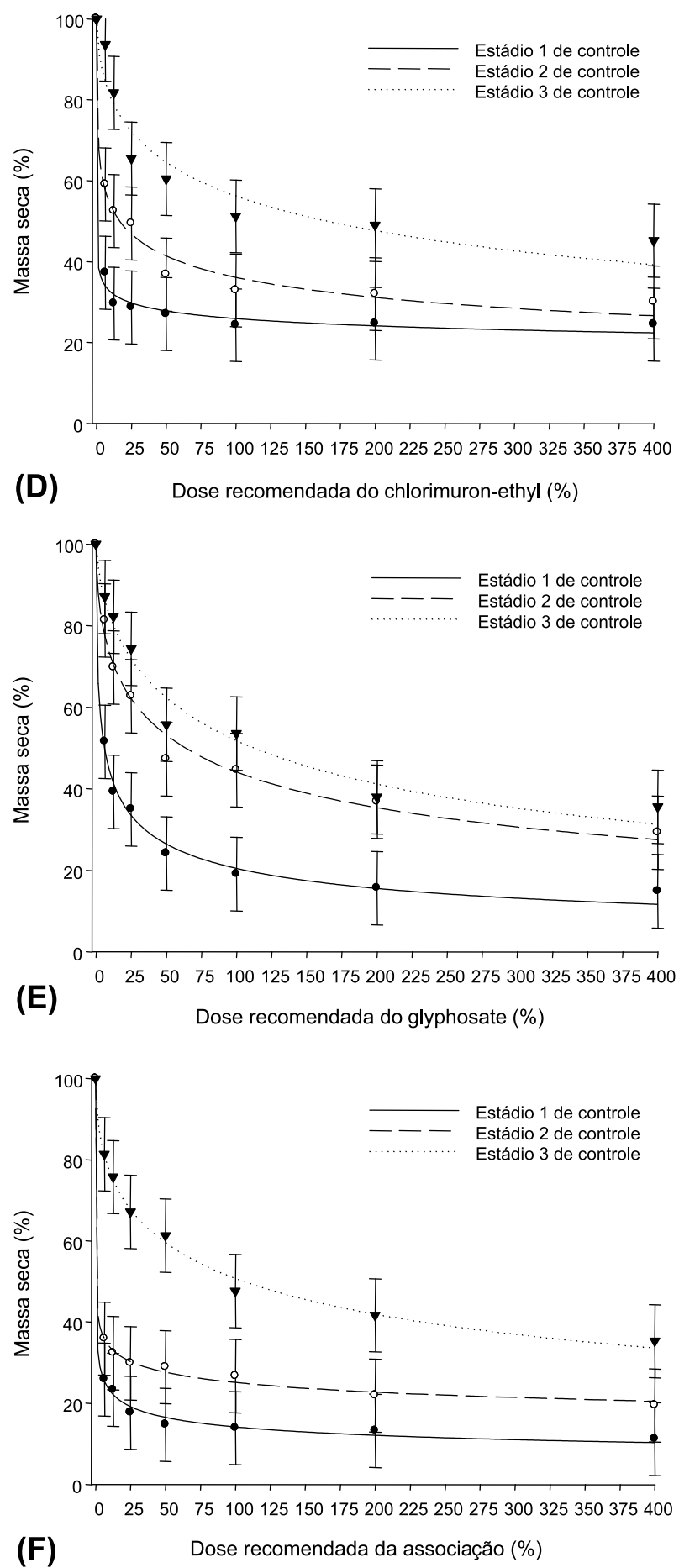

Figura 3 - Percentual de controle e fitomassa seca da parte aérea no biótipo 17 de C. sumatrensis aos 28 dias após aplicação de doses dos herbicidas chlorimuron-ethyl (A e D) e glyphosate (B e E) e da associação deles (C e F). As barras verticais representam $95 \%$ de intervalo de confiança. 
à observada no presente estudo. O FS para o glyphosate com os valores do $\mathrm{C}_{50}$ e $\mathrm{GR}_{50}$ foi de 1,29 e 6,69 do primeiro para o segundo estádio do biótipo, respectivamente (Tabelas 3 e 4). Já

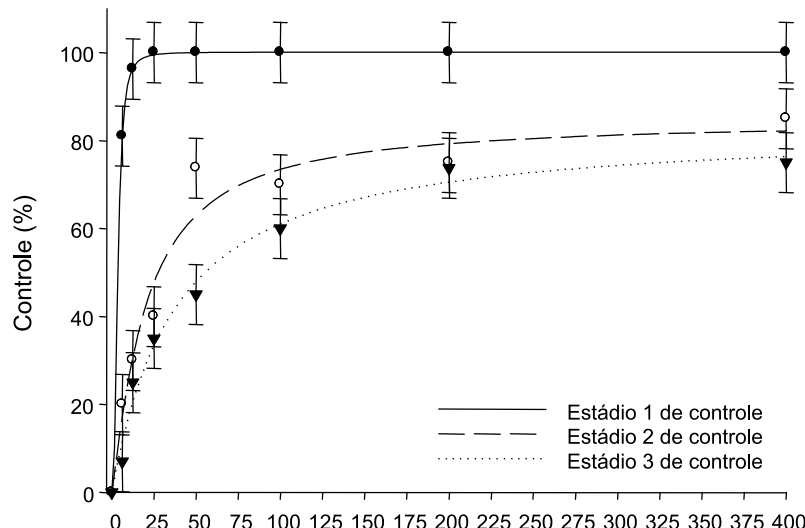

(A)

Dose recomendada do chlorimuron-ethyl (\%)
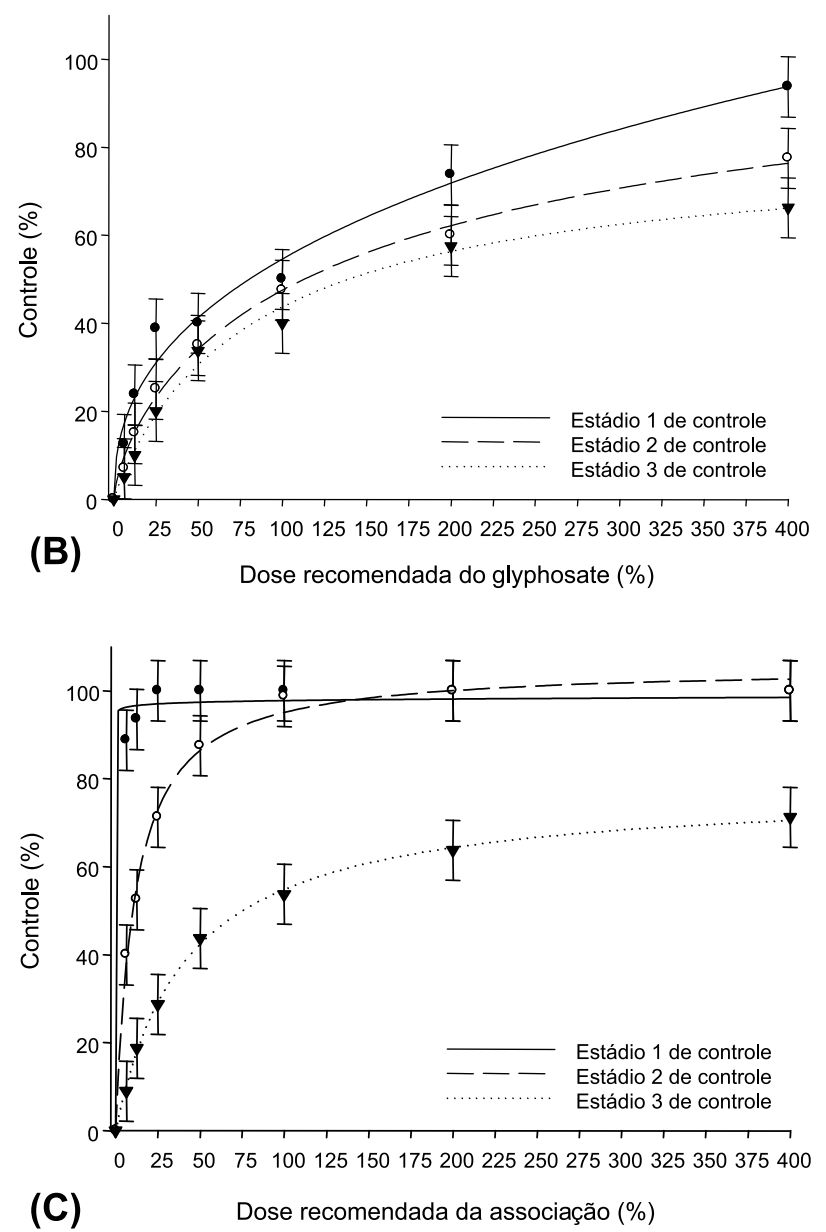

do primeiro para o terceiro estádio, os valores do $\mathrm{C}_{50}$ e do $\mathrm{GR}_{50}$ não foram calculados, pois foram maiores que a dose de 2.880 g e.a. ha ${ }^{-1}$, ficando fora das doses avaliadas no estudo
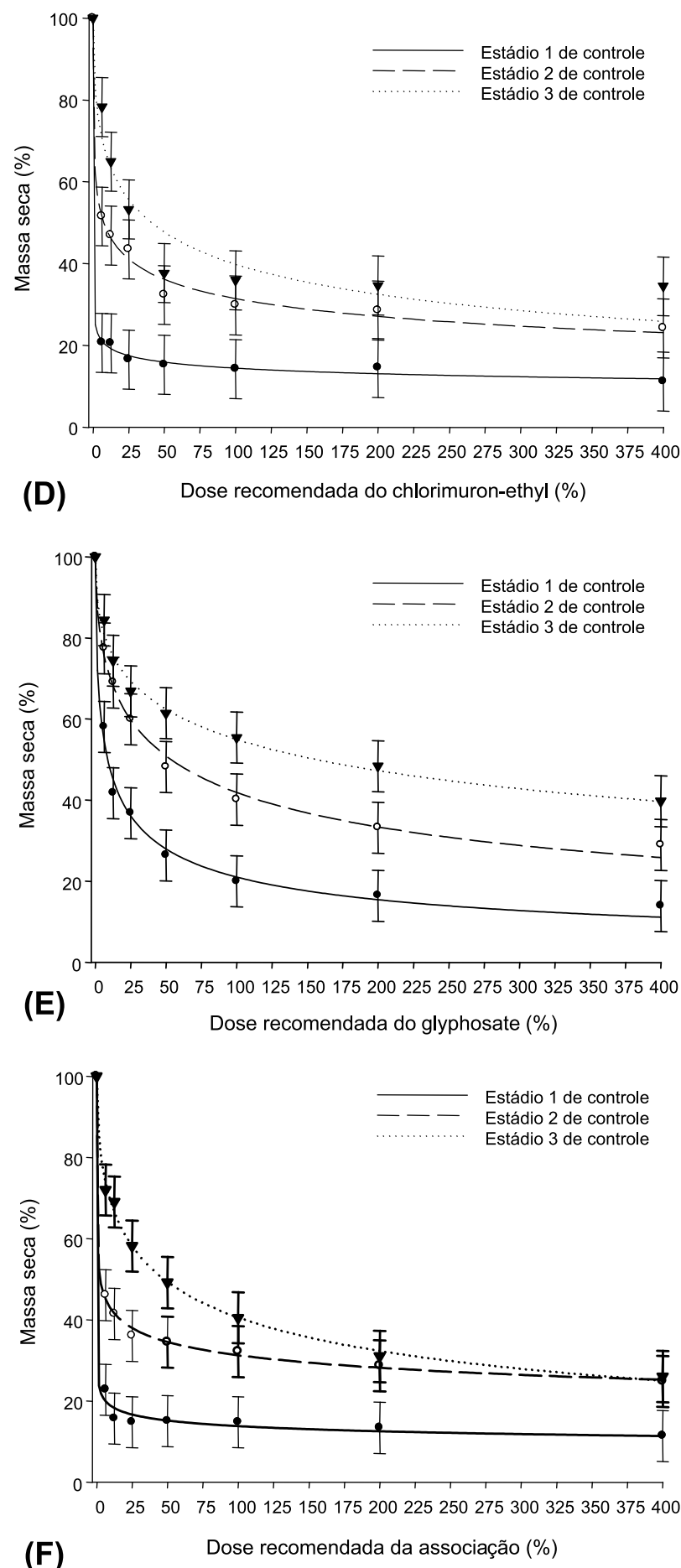

Figura 4 - Percentual de controle e fitomassa seca da parte aérea no biótipo 20 de $C$. sumatrensis aos 28 dias após aplicação de doses dos herbicidas chlorimuron-ethyl (A e D) e glyphosate (B e E) e da associação deles (C e F). As barras verticais representam $95 \%$ de intervalo de confiança. 
para o biótipo 5 (Tabelas 2 e 4). Para o herbicida glyphosate, os valores do $\mathrm{C}_{50}$ e do $\mathrm{GR}_{50}$, calculados por meio das equações estabelecidas pelas porcentagens de controle e de fitomassa seca do biótipo, comprovam a existência de resistência ao herbicida, independentemente do estádio de desenvolvimento em que ele é aplicado. A resistência de buva ao glyphosate foi identificada por Vargas et al. (2007) e Lamego \& Vidal (2008); atualmente, o biótipo está presente na maioria das lavouras do RS.

Os resultados demonstram que o biótipo 5 apresenta resistência ao herbicida glyphosate, mas é suscetivel à associação de chlorimuronethyl com glyphosate no primeiro estádio de desenvolvimento (altura de 0,5-1 cm e 3-4 folhas), não caracterizando resistência múltipla à associação dos herbicidas. Assim, para alcançar $100 \%$ de controle do biótipo, é necessário relacionar a dose da associação (glyphosate + chlorimuron) ao estádio de desenvolvimento do biótipo no momento da aplicação.

Nos biótipos 17 e 20, observou-se controle de $100 \%$, no primeiro estádio, com as doses de $50 \%\left(10 \mathrm{~g} \mathrm{ha}^{-1}\right)$ e $12,5 \%\left(2,5 \mathrm{~g} \mathrm{ha}^{-1}\right)$ de chlorimuron-ethyl, respectivamente (Figuras 3 e 4A). Contudo, aplicando a maior dose do chlorimuron $\left(400 \%\right.$ ou $\left.80 \mathrm{~g} \mathrm{ha}^{-1}\right)$, tanto no segundo quanto no terceiro estádio de desenvolvimento dos biótipos foram observados controles insatisfatórios, entre 70 e $80 \%$ (Figuras 3 e 4A). O FS calculado com os valores do $\mathrm{C}_{50}$, para os biótipos 17 e 20 , para o chlorimuron foi de 17,1 e 4,9 do primeiro para o segundo estádio e de 20,5 e 15,3 do primeiro para o terceiro estádio, respectivamente (Tabela 2). Já o FS calculado com os valores do $\mathrm{GR}_{50}$, para os biótipos 17 e 20, para chlorimuron foi de 15,8 e 8,3 do primeiro para o segundo estádio e de 155,9 e 44,1 do primeiro para o terceiro estádio, respectivamente (Tabela 2). Esses resultados demonstram a suscetibilidade dos biótipos 17 e 20 ao herbicida chlorimuron-ethyl quando aplicado no primeiro estádio de desenvolvimento (altura de $0,5-1 \mathrm{~cm}$ e 3-4 folhas) (Figuras 3 e 4A).

Para o glyphosate, observou-se controle de $100 \%$ dos biótipos 17 e 20 , no primeiro estádio de desenvolvimento, com
$200 \%$ ( 1.440 g e.a. ha ${ }^{-1}$ ) e $400 \%$ da dose (2.880 g e.a. ha ${ }^{-1}$ ), respectivamente (Figuras 3 e 4B). No entanto, no segundo estádio, o biótipo 17 teve controle de $100 \%$ para a maior dose de glyphosate ( $400 \%$ ou 2.880 g e.a. ha-1); já no biótipo 20 a mesma dose teve controle de $70 \%$ (Figuras 3 e 4B). No terceiro estádio dos biótipos 17 e 20 , o controle com glyphosate foi de 70 e $65 \%$ na maior dose utilizada $(400 \%$ ou 2.880 g e.a. ha-1), respectivamente (Figuras 3 e 4B). O FS calculado com os valores do $C_{50}$, para os biótipos 17 e 20, para o glyphosate foi de 1,3 e 1,4 do primeiro para o segundo estádio e de 1,6 e 1,7 do primeiro para o terceiro estádio, respectivamente (Tabela 2). Já o FS calculado com os valores do $\mathrm{GR}_{50}$, para os biótipos 17 e 20, para o glyphosate foi de 10,5 e 6,1 do primeiro para o segundo estádio e de 18,6 e 17,7 do primeiro para o terceiro estádio, respectivamente (Tabela 2). Esses resultados demonstram a suscetibilidade dos biótipos 17 e 20 ao herbicida glyphosate no primeiro estádio de desenvolvimento. Contudo, observa-se que os biótipos 17 e 20 no primeiro estádio de desenvolvimento são suscetíveis ao herbicida chlorimuron-ethyl, porém, no mesmo estádio, os biótipos apresentaram menor sensibilidade à aplicação de glyphosate.

$\mathrm{Na}$ associação de chlorimuron-ethyl + glyphosate, observou-se que os biótipos 17 e 20 foram controlados no primeiro estádio com $25 \%$ (5 g +180 g e.a. ha $\left.{ }^{-1}\right)$ e $12,5 \%$ da dose $\left(2,5 \mathrm{~g}+90 \mathrm{~g}\right.$ e.a. $\left.\mathrm{ha}^{-1}\right)$, respectivamente (Figuras 3 e 4C). No segundo estádio, obtevese controle de $100 \%$ dos biótipos 17 e $20 \mathrm{com}$ uso de $50 \%$ (10 g +360 g e.a. ha-1) e de $100 \%$ da dose $\left(20 \mathrm{~g}+720 \mathrm{~g}\right.$ e.a. ha-1 ${ }^{-1}$, respectivamente. No entanto, quando se aplicou a maior dose da associação $(400 \%$ ou $80 \mathrm{~g}+$ 2.880 g e.a. ha $^{-1}$ ), no terceiro estádio de desenvolvimento, observou-se controle insatisfatório dos biótipos, entre 60 e $70 \%$ (Figuras 3 e 4C). Esses resultados demonstram a suscetibilidade dos biótipos 17 e 20 à associação dos herbicidas chlorimuron-ethyl + glyphosate somente no primeiro e no segundo estádio (Figuras 3 e 4C). O FS calculado com os valores do $\mathrm{C}_{50}$, para o biótipo 17 , para a associação (chlorimuron-ethyl + glyphosate) foi de 2,2 do primeiro para o segundo estádio e de 32,2 do primeiro para o terceiro estádio (Tabela 2); no biótipo 20, o FS foi de 2,9 do primeiro para o 
segundo estádio e de 21,5 do primeiro para o terceiro estádio (Tabela 3). Já o FS calculado com os valores do $\mathrm{GR}_{50}$, para o biótipo 17 , na associação de chlorimuron-ethyl + glyphosate não diferiu do primeiro para o segundo estádio e foi de 108,3 do primeiro para o terceiro estádio (Tabela 2); no biótipo 20, o FS foi de 3,05 do primeiro para o segundo estádio e de 66,1 do primeiro para o terceiro estádio (Tabela 3).

Na Tabela 4, observou-se interação significativa na variável densidade tricomática entre os biótipos e os estádios de desenvolvimento. No primeiro estádio de desenvolvimento, o biótipo 17 evidenciou a maior quantidade $\left(16,8\right.$ tricomas $\left.\mathrm{mm}^{-2}\right)$, seguido do biótipo 5 (11,6 tricomas $\left.\mathrm{mm}^{-2}\right)$. No entanto, o biótipo 20 apresentou a menor quantidade (7,4 tricomas $\left.\mathrm{mm}^{-2}\right)$, não diferindo do biótipo 2 , que apresentou 8,4 tricomas $\mathrm{mm}^{-2}$. A menor sensibilidade do biótipo 17, no primeiro estádio, ao herbicida chlorimuron-ethyl pode estar relacionada à maior densidade tricomática (Tabela 4).

No segundo e terceiro estádios de desenvolvimento, o biótipo 17 evidenciou a maior quantidade de tricomas: 11,3 e 11,6 $\mathrm{mm}^{-2}$, respectivamente (Tabela 4). Já o biótipo 2 evidenciou a menor quantidade no segundo e terceiro estádios de desenvolvimento, respectivamente, $\left(9,2\right.$ e 9,5 $\left.\mathrm{mm}^{-2}\right)$ (Tabela 4). Contudo, os biótipos 5 e 20 não diferiram do biótipo 2, no segundo e terceiro estádios. No entanto, para o biótipo 20 houve aumento na densidade tricomática do primeiro para o segundo estádio, e no biótipo 2 não houve alteração na densidade tricomática com o seu desenvolvimento. Já nos biótipos 17 e 5 observou-se diminuição da densidade tricomática do primeiro para o segundo estádio de desenvolvimento (Tabela 4).

Segundo Procópio et al. (2003), a alta densidade tricomática da superficie adaxial foi considerada uma das barreiras foliares potenciais à penetração de herbicidas em C. bonariensis. A presença de tricomas na superficie adaxial da folha pode interceptar gotas pulverizadas, impedindo que estas alcancem a epiderme propriamente dita, o que prejudica a absorção do herbicida (Yamashita \& Guimarães, 2011). As informações sobre a eficiência da absorção de herbicidas pelos tricomas e a translocação destes para as células epidérmicas são ainda parcialmente conhecidas (Hess \& Falk, 1990). Segundo Iost $\&$ Raetano (2010), os surfatantes organossiliconados foram mais eficientes na redução da tensão superficial e proporcionaram maior molhamento da superfície foliar de Euphorbia heterophylla com tricomas; assim, podem ser usados como alternativa para superar eventuais efeitos negativos dos tricomas na absorção de herbicidas.

Quanto à densidade estomática, não houve interação entre os biótipos e os estádios de desenvolvimento (Tabela 4). Entretanto, evidenciou-se diminuição do número de estômatos dos biótipos com o seu desenvolvimento do primeiro $\left(84,2\right.$ estômatos $\left.\mathrm{mm}^{-2}\right)$ até o terceiro estádio $\left(65,8\right.$ estômatos $\left.\mathrm{mm}^{-2}\right)$.

Tabela 4 - Densidades de tricomas e de estômatos na superfície adaxial dos biótipos 2, 5, 17 e 20 de C. sumatrensis, em três estádios de desenvolvimento

\begin{tabular}{|c|c|c|c|c|c|c|}
\hline \multirow{3}{*}{ Biótipo } & \multicolumn{3}{|c|}{$\begin{array}{l}\text { Densidade tricomática } \\
\left(\text { tricomas } \mathrm{mm}^{-2}\right)\end{array}$} & \multicolumn{3}{|c|}{$\begin{array}{l}\text { Densidade estomática } \\
\text { (estômatos } \mathrm{mm}^{-2} \text { ) }\end{array}$} \\
\hline & \multicolumn{3}{|c|}{ Estádio de desenvolvimento } & \multicolumn{3}{|c|}{ Estádio de desenvolvimento } \\
\hline & $1^{\mathrm{o}}$ & $2^{\underline{O}}$ & $3^{-}$ & $1^{\underline{o}}$ & $2^{-0}$ & $3^{-0}$ \\
\hline 02 & $8,40 \mathrm{cA}^{1 /}$ & $9,20 \mathrm{bA}$ & $9,50 \mathrm{bA}$ & $84,2^{\mathrm{ns}}$ & 73,7 & 63,2 \\
\hline 05 & $11,6 \mathrm{bA}$ & $9,50 \mathrm{bB}$ & $10,3 \mathrm{bB}$ & 84,2 & 73,7 & 73,7 \\
\hline 17 & $16,8 \mathrm{aA}$ & $11,3 \mathrm{aB}$ & $11,6 \mathrm{aB}$ & 84,2 & 73,7 & 57,9 \\
\hline 20 & $7,40 \mathrm{cB}$ & $10,0 \mathrm{bA}$ & $9,70 \mathrm{bA}$ & 84,2 & 84,2 & 68,4 \\
\hline Média & 11,0 & 10,0 & 10,3 & $84,2 \mathrm{~A}$ & $76,3 \mathrm{~B}$ & $65,8 \mathrm{C}$ \\
\hline $\mathrm{CV}^{2 /}(\%)$ & \multicolumn{3}{|c|}{11,9} & \multicolumn{3}{|c|}{10,9} \\
\hline
\end{tabular}

1/ Médias seguidas de mesma letra, minúsculas nas colunas e maiúsculas nas linhas, não diferem estatisticamente entre si pelo agrupamento de médias do teste de Scott-Knott $(\mathrm{p}<0,05)$; ${ }^{\text {ns }}$ não significativo a $5 \%$ de probabilidade; ${ }^{2}$ Coeficiente de Variação. 
Procópio et al. (2003) determinaram que a baixa densidade estomática em $C$. bonariensis foi considerada uma das principais barreiras à penetração de herbicidas. Para Tuffi Santos et al. (2006), a alta densidade pode favorecer a penetração do glyphosate em plantas de eucalipto nas quais a presença de estômatos seja grande, principalmente na face adaxial da epiderme foliar, onde o contato com a calda herbicida aplicada é mais provável. Um fator ligado à penetração dos herbicidas pelos estômatos é a cutícula sobre as células-guarda, que parece ser mais fina e mais permeável (menor teor de cera epicuticular), constituindo-se numa barreira menos rígida à penetração de herbicidas (Hess \& Falk, 1990). Por isso, a maior densidade estomática dos biótipos no primeiro estádio de desenvolvimento pode ser considerada um fator positivo do ponto de vista do controle da espécie em se tratando de aplicação de herbicidas, pois a absorção tende a ser maior.

De modo geral, foram observadas, para os biótipos 2, 5, 17 e 20 de C. sumatrensis, diferenças nos níveis de controle, produção de fitomassa seca da parte aérea, $\mathrm{C}_{50}, \mathrm{GR}_{50}$ e FS para os tratamentos herbicidas avaliados. Para o chlorimuron-ethyl, essas diferenças foram influenciadas pelos estádios de desenvolvimento: quanto mais avançado o estádio, menor a sensibilidade. Essa menor sensibilidade dos biótipos pode ser influenciada pela densidade tricomática entre os estádios de desenvolvimento dos biótipos. Nesse sentido, a hipótese sugerida para explicar a menor sensibilidade dos biótipos 2, 5, 17 e 20 de C. sumatrensis ao chlorimuron, em estádios vegetativos acima de seis folhas (maiores de $10 \mathrm{~cm}$ ), é a redução da absorção devido a fatores relacionados à anatomia externa da folha, como a presença de tricomas.

Os resultados deste trabalho evidenciam que os estádios de desenvolvimento de C. sumatrensis afetam significativamente o nivel de sensibilidade aos herbicidas chlorimuron-ethyl e glyphosate e à associação destes. Os biótipos 17 e 20 de C. sumatrensis não foram suscetíveis ao chlorimuron no segundo e no terceiro estádio vegetativo avaliado; no terceiro estádio de desenvolvimento, os biótipos não foram suscetiveis à associação de chlorimuron-ethyl + glyphosate. O biótipo 5 foi resistente ao herbicida glyphosate, independentemente do estádio de desenvolvimento. Quanto às características morfológicas da folha, o biótipo 17 apresentou maior número de tricomas em todos os estádios de desenvolvimento. No entanto, a densidade estomática diminui com o desenvolvimento dos biótipos. Assim, sugere-se que a maior presença de tricomas verificada com o desenvolvimento dos biótipos de C. sumatrensis possa interferir na penetração dos herbicidas, prejudicando o controle dos biótipos. Por isso, o controle de $C$. sumatrensis com chlorimuronethyl ou chlorimuron+glyphosate deve ser realizado em estádio vegetativo de até quatro folhas $(1 \mathrm{~cm})$.

\section{LITERATURA CITADA}

SISTEMA DE AGROTÓXICOS FITOSSANITÁRIOS -

AGROFIT. Disponível em: $<$ http://extranet. agricultura.gov.br /agrofit_cons/principal_agrofit_cons $>$. Acesso em: 9 mar. 2013.

BRUCE, J.; KELLS, J. Horseweed (C. canadensis) control in no-tillage soybeans (Glycine max) with preplant and preemergence herbicides. Weed Technol., v. 4, n. 3, p. 642-647, 1990.

CHRISTOFFOLETI, P. J.; LÓPEZ-OVEJERO, R. F. Resistência das plantas daninhas a herbicidas: definições, bases e situação no Brasil e no mundo. In:

CHRISTOFFOLETI, P. J. (Coord.). Aspectos de resistência de plantas daninhas a herbicidas. 3.ed. Piracicaba:

Associação Brasileira de Ação a Resistência de Plantas aos Herbicidas - HARAC-BR, 2008. p. 9-34.

FRANS, R. et al. Experimental design and techniques for measuring and analyzing plant responses to weed control practices. In: CAMPER, N. D. Research methods in weed science. 3.ed. Champaign: Southern Weed Science Society, 1986. p. 29-46.

GEIGER, D. R.; FUCHS, M. A. Inhibitors of aromatic amino acid biosynthesis (glyphosate). In: BÖGER, P.; WAKABAYASHI, K.; HIRAI, K. (Ed.). Herbicide classes in development. Berlin: Springer-Verlag, 2002. p. 59-85.

HEAP, I. International survey of resistant weeds. Disponível em: $<$ http://www. weedscience.org $>$. Acesso em: 20 fev. 2013.

HESS, F. D.; FALK, R. H. Spontaneous lysosomal storage disease caused by Sida carpinifolia (Malvaceae) poisoning in cattle. Weed Sci., v. 38, n. 3, p. 280-288, 1990. 
IOST, C. A. R.; RAETANO, C. G. Tensão superficial dinâmica e ângulo de contato de soluções aquosas com surfatantes em superfícies artificiais e naturais. Eng. Agríc., v. 30, n. 4 , p. $670-680,2010$.

KOGER, C. H. et al. Glyphosate-resistant horseweed (Conyza canadensis) in Mississippi. Weed Technol., v. 18, n. 3, p. 820-825, 2004.

KRAUS, J. E. et al. Astra blue and basic fuchsin double staining of plant materials. Biot. Histochem., v. 73, n. 5, p. 235-243, 1998.

LAMEGO, F. P.; VIDAL, R. A. Resistência ao glyphosate em biótipos de $C$. bonariensis e C. canadensis no Estado do Rio Grande do Sul, Brasil. Planta Daninha, v. 26, n. 2, p. 467-471, 2008.

MOREIRA, M. S. et al. Herbicidas alternativos para o controle de biótipos de Conyza bonariensis e C. canadensis resistentes ao herbicida glyphosate. Planta Daninha, v. 28, n. 1, p. 167-175, 2010.

PROCÓPIO, S. O. et al. Estudos anatômicos de folhas de espécies de plantas daninhas de grande ocorrência no brasil. III Galinsoga parviflora, Crotalaria incana, Conyza bonariensis e Ipomoea cairica. Planta Daninha, v. 21, n. 1, p. 1-9, 2003.

RODELLA, R. A. et al. Anatomia comparativa foliar e caulinar de duas espécies daninhas de Merremia

(Convolvulaceae). Científica, v. 21, n. 2, p. 345-353, 1993.

RODRIGUES, B. N.; ALMEIDA, F. S. Guia de herbicidas. 6.ed. Londrina: 2011. 6961 p.

SANTOS, G. Resistência múltipla ao glyphosate e ao chlorimuron-ethyl em biótipos de Conyza sumatrensis. 2012. 87 f. Dissertação (Mestrado em Produção de Plantas) Universidade Estadual de Maringá, Maringá, 2012.
SIGMAPLOT - Scientific graphing software. Version 10.0, 2007.

SILVA, F. A. S.; AZEVEDO, C. A. V. Principal components analysis in the software assistat-statistical attendance. In: WORLD CONGRESS ON COMPUTERS IN AGRICUltURE, 7., 2009, Reno. Proceedings... Reno-NVUSA: American Society of Agricultural and Biological Engineers, 2009.

STREIBIG, J. C. Herbicide bioassay. Weed Res., v. 28, n. 1, p. 479-484, 1988.

TELES, A. M.; BORGES, R. A. X.; HEIDEN, G. Conyza In: Lista de espécies da flora do Brasil. 2013. Jardim Botânico do Rio de Janeiro. Disponível em: <http://floradobrasil. jbrj.gov.br/ jabot/floradobrasil/FB5288>. Acesso em: 25 jun. 2013.

THEBAUD, C.; ABBOTT, R. J. Characterization of invasive Conyza species (Asteraceae) in Europe: Quantitative trait and isozyme analysis. Am. J. Bot., v. 82, n. 1, p. 360-368, 1995.

TUFFI SANTOS, L. D. et al. Características da epiderme foliar de eucalipto e seu envolvimento com a tolerância ao glyphosate. Planta Daninha, v. 24, n. 3, p. 503-520, 2006.

VANGESSEL, M. J. et al. Influence of glyphosate-resistant horseweed (Conyza canadensis) growth stage on response to glyphosate applications. Weed Technol., v. 23, n. 1, p. 49-53, 2009.

VARGAS, L. et al. Buva (C. bonariensis) resistente ao glyphosate na região Sul do Brasil. Planta Daninha, v. 25, n. 3, p. 573-578, 2007.

YAMASHITA, O. M.; GUIMARÃES, S. C. Biologia e resistência a herbicidas de espécies do gênero Conyza. Amb. Guarapuava, v. 7, n. 2, p. 383-398, 2011. 